\title{
Trabajadores y afectos en clave histórica. Una mirada desde la historia social con perspectiva de género
}

\author{
Workers and Affections in a Historical Key A Review from Social History with Gender Perspective
}

\author{
Florencia D'Uva \\ Universidad de Buenos Aires, Argentina \\ florenciaduva87@gmail.com
}

\section{ReSUMEN:}

Este trabajo se propone contribuir a la reflexión y conocimiento de la historia de los sentimientos y las emociones considerando puntualmente cómo se han abordado estos ejes problemáticos en la historia del mundo del trabajo. Tomará como disparador el caso de una denuncia policial realizada en la localidad bonaerense de Las Flores en 1909, con el fin de analizar los sentimientos, emociones, comportamientos, vínculos, valores, normas esperables de conducta, tensiones y conflictos que vivenciaron y expresaron los sujetos implicados en esta situación particular, prestando especial atención a las marcas de clase, edad y género entramadas en sus experiencias.

Palabras ClaVe: Trabajadores, Afectos, Emociones, Historia social, Género.

\section{Abstract:}

This paper seeks to contribute to the reflection and knowledge of the History of Feelings and Emotions especially considering how these problematic topics have been approached in Labor History. It will take the case of a police report that took place in Las Flores town, in Buenos Aires province, to analyze the feelings, emotions, relations, values, expected standards of behavior, tensions and conflicts experimented and expressed by the subjects involved in this particular situation, paying special attention to class, gender and age marks implicated in their experiences.

KEYWORDS: Workers, Affections, Emotions, Social history, Gender.

\section{INTRODUCCIÓN}

Hace unos años, al finalizar mi exposición en un congreso de Historia, Archivos y Género sobre los desafíos metodológicos a los que me enfrentaba al rastrear a las mujeres y la vida familiar de los trabajadores ferroviarios, una colega se me acercó para contarme de un caso que me podía interesar. Se trataba de una denuncia policial realizada en el pueblo de Las Flores a principios del siglo XX, en la que una mujer acusaba a un foguista del Ferrocarril Sud de haber abusado de ella y de sus hijas de dieciocho y quince años de edad. Según resumió la colega, el trabajador había entablado un vínculo con la mujer que realizó la denuncia, a la que luego había dejado por una de sus hijas. Pero también a esta hija la había abandonado, para fugarse con su hermana menor, hecho que había desencadenado la denuncia en cuestión. Enseguida me interesé por esa fuente, que se me presentaba como el documento ideal que prometía iluminar todo aquello por lo que yo me venía preguntando y que tan difícil me resultaba responder, más allá de las lecturas a contrapelo, los cruces de evidencias y los ejercicios de imaginación histórica ensayados. Luego de viajar a Las Flores, visitar el Archivo Municipal, tomar contacto con la copia de la denuncia que allí conservaban, leerla y enterarme de que había inspirado distintas obras teatrales, surgieron nuevas preguntas e inquietudes. Así fue que se me presentó la cuestión de cómo pensar los afectos, cómo hacer una historia de los trabajadores del ferrocarril que tuviera en cuenta la dimensión sentimental, emocional y afectiva, y de qué manera incorporar esta dimensión a la perspectiva de historia social y género de la que partía mi investigación ${ }^{1}$. La denuncia fue el puntapié para realizar un primer ejercicio de indagación que pude compartir en una mesa sobre emociones 
y sentimientos en las XIII Jornadas de Historia de las Mujeres y VIII Congreso de Estudios de Género realizadas en julio del $2017^{2}$. Lejos de clausurar mi inquietud, el hecho de leer y escuchar a otras investigadoras de Argentina y Latinoamérica que estaban pensando en clave afectiva distintos problemas históricos disparó nuevos interrogantes sobre este campo de estudios y sobre sus cruces posibles con la historia social del trabajo con perspectiva de género.

En este escrito me propongo contribuir a la reflexión y conocimiento de la historia de los sentimientos y las emociones a partir de considerar puntualmente cómo se han abordado estos ejes problemáticos en la historia del mundo del trabajo. Además de tomar la denuncia como un disparador para reflexionar sobre la cultura afectiva y moral, los vínculos, valores, expectativas, normas esperables de conducta, tensiones y conflictos vividos por los sectores trabajadores, me interesa aquí interrogarme por los recorridos y derroteros historiográficos de este campo de estudios en Argentina. En este mismo sentido, se buscará reflexionar en torno a la ausencia o poco interés que ha demostrado la historia social del trabajo por abordar la dimensión emocional y sentimental de los trabajadores. Al realizar un recorrido por distintos momentos historiográficos, el objetivo es distinguir y detenerse en una serie de investigaciones que permitan identificar los intereses de diversas agendas a lo largo del tiempo, y repensar cómo algunas lecturas pueden posibilitar un conocimiento acerca de un campo de estudios que, aunque incipiente en la historiografía laboral argentina, tiene un largo camino por delante.

\section{UnA DENUNCIA POLICIAL PARA PENSAR los AFECTOS}

El 15 de enero de 1909 Angélica Solores se presentó ante el comisario policial de la localidad bonaerense de Las Flores, Marcos Andrade, para levantar una denuncia contra Bonifacio Estrella ${ }^{3}$. A partir de las declaraciones de la mujer, una de sus hijas y el acusado, así como de las propias notas y apreciaciones del comisario encargado de registrarlas, me propongo reflexionar sobre la cultura afectiva y moral que atravesaba a quienes de una u otra manera participaron en la denuncia, prestando especial atención a las marcas de clase, edad y género entramadas en sus experiencias.

Una amplia literatura ha utilizado expedientes judiciales como fuente privilegiada para recuperar la voz de los sujetos que no han dejado registros de puño propio, cuyas experiencias, concepciones y percepciones, por ende, resultan más difícil de rastrear (Farge, 1991; Ginzburg, 1999; Johnson, 2007; Putnam, 2013; Zemon Davis, 1987). El análisis de las estrategias desplegadas por las personas pertenecientes a los sectores populares -esclavos, trabajadores, varones y mujeres pobres- que se presentaban ante canales formales de la justicia permite aprehender quiénes eran estos sujetos, cómo se presentaban a sí mismos y sus vidas, cuáles eran sus nociones de lo justo, entre otras cuestiones. Posibilitan recuperar su agencia y trazos de sus experiencias a pesar de los sesgos y distorsiones que es necesario sortear al trabajar con este tipo de documentos. Asimismo, en la agenda local, los recientes trabajos de María Bjerg $(2017,2018)$ han utilizado expedientes judiciales para indagar el universo emocional de los migrantes y las migrantes italianas y españolas que a principios del siglo XX iniciaron demandas judiciales en Buenos Aires por delito de bigamia o adulterio. Insertos en una agenda historiográfica más amplia (Albornoz Vasquéz, 2016; Barclay, 2017), estos artículos reflexionan sobre el potencial de los expedientes judiciales para el estudio de la experiencia migratoria y su dimensión emocional.

En el presente trabajo, y si bien la fuente no constituye un expediente judicial sino una denuncia ante la autoridad policial - por ende, no se buscaron pruebas ni testigos, no hubo abogados implicados y tan solo se tomó declaración a los sujetos directamente involucrados en la contienda-, se busca rastrear y examinar algunos de los sentimientos y emociones expresadas por Angélica, su hija Dolores y Bonifacio, así como los vínculos afectivos establecidos entre ellos. Al consider que el análisis a escala reducida ilumina dimensiones subjetivas de procesos y problemáticas históricas, permite advertir actores que en un abordaje macro pasarían desapercibidos, y contribuye a complejizar y/o resignificar interpretaciones generales y habilitar nuevos 
interrogantes, pretendo utilizar la denuncia como una ventana a la cultura afectiva y moral, las experiencias emocionales y las formas de vida de los pobladores de una localidad de Buenos Aires hacia la segunda década del siglo XX. El ejercicio toma como punto de partida algunas de las intenciones, recaudos y herramientas metodológicas formuladas desde la historia social y cultural, y desde el abordaje microhistórico (Darnton, 1984; Ginzburg, 2006; Levy, 1991; Secreto, 2014; Thompson, 1976; Zemon Davis, 1982). Particularmente, se toman en cuenta las advertencias sobre cómo trabajar con experiencias individuales y casos singulares, reconstruir los contextos históricos en los que estos tuvieron lugar, rastrear la agencia y capacidad de intervención de los sujetos a pesar de los límites externos y exprimir las posibilidades de análisis que permite la reducción de escala.

\section{LA DENUNCIA}

$\mathrm{Al}$ presentarse ante la autoridad policial aquel 15 de enero Angélica debió responder algunas preguntas que le formuló el comisario. En sus respuestas, informó que era santiagueña ${ }^{4}$, de 38 años de edad, viuda "no sabe de quien”, y que vivía en una casa cercana a la estación del ferrocarril. Respecto a su viudez, explicó que se había casado dos veces, la primera con Francisco Carreño, con quien había tenido dos hijas, Micaela y Dolores, de 18 y 15 años de edad respectivamente. Según contaba, eran "muy felices", pero un día Francisco se fue a trabajar a la cosecha y, como estuvo cuatro años sin volver ni dar señales de vida, ella lo creyó muerto y volvió a contraer matrimonio con Casimiro Reyes, con quien tuvo otros tres hijos de los que no dio más información. Finalmente, relató que Reyes también la había abandonado mucho tiempo antes de la declaración sin saber ella por qué, y así es que por no saber si sus maridos estaban muertos o no, decía que no sabía de cuál de ellos era viuda. A continuación, contó que hacía un año había conocido a Bonifacio Estrella, un foguista de tren que había querido casarse enseguida con ella, pero que por miedo a que le pasara lo mismo que con los otros maridos no le dio el sí, aunque aceptó "vivir arrimada con el pero guardandolé el rispeto como si fuera su esposo endeveras" . Relató que al principio Bonifacio se había portado bien, que era cariñoso con sus hijas y corría con los gastos de la casa. Pero que, transcurrido un tiempo, ella se dio cuenta de que entre él y su hija Micaela había algo, y no se había equivocado, pues cuando aclaró las cosas la muchacha estaba embarazada, y "el sedutor era su propio marido". Agregaba que, debido a esta situación, se había generado un gran barullo entre ellos, pero que, como se habían acostumbrado a vivir todos juntos, arreglaron las cosas y Bonifacio quedó como marido de Micaela, "con eya [Angélica] nihablarse". Afirmaba que, a pesar de sentir que perdía un marido joven y con empleo, dejó que las cosas pasaran; entregó a la pareja su propia cama matrimonial y ella se fue a dormir al catre que antaño fuera de Micaela, pero antes de que la muchacha diera a luz, Estrella se fugó de la casa junto a Dolores, la hermana de Micaela. Luego de aclarar que si estuviera en otras condiciones no pediría nada, y que después de lo ocurrido era muy difícil encontrar otro hombre que quisiera hacerse cargo de la familia, Angélica hacía la denuncia "pidiendo a la autoridad que le hagan justicia obligando a Estrella a volver a la casa y que se case con cualquiera de sus hijas" ${ }^{\text {. }}$ Agregaba que, si no quisiera casarse con ninguna de las muchachas, ella misma, a pesar del resentimiento que le guardaba, estaba dispuesta a sacrificarse y casarse con él con tal de salvar el honor de la familia.

Esta es, brevemente resumida, la denuncia presentada por Angélica ante el comisario de Las Flores, aquel día del verano de 1909. La misma da cuenta de un problema conyugal que, al no haberse podido resolver entre las partes involucradas, una de ellas decidió hacer público ante la autoridad policial con la esperanza de encontrar una solución. Gracias al hecho de que Angélica decidió realizar una denuncia es que se puede conocer con bastante detalle un momento de su vida, algo de los vínculos interpersonales establecidos entre ella, sus hijas y sus parejas, sobre quiénes eran, cómo vivían, cómo se presentaban a sí mismas y a los hechos, cómo justificaban sus acciones, cuáles eran sus expectativas. También permite saber sobre la diversidad de arreglos que podía existir en las relaciones afectivas y familiares, y las respuestas ensayadas frente al conflicto. A 
su vez, la denuncia de Angélica permite indagar en las estrategias y márgenes de acción, autonomía, resistencia y creatividad con que podían contar ciertas mujeres en una situación de vulnerabilidad. Pero las estrategias individuales siempre se despliegan dentro de un marco de posibilidades históricamente situadas, por eso resulta importante inscribir esta historia en su contexto.

\section{LAS FloRes HaCia 1909}

La denuncia ocurrió en un lugar y coyuntura específicos: un pueblo del centro de la provincia de Buenos Aires hacia la segunda década del siglo XX. Restituir algo de ese contexto otorga sentidos y permite comprender algunas de las experiencias, ideas y costumbres compartidas por los actores involucrados, quienes entendían e interpretaban el mundo de una manera determinada, a partir de su propia cultura. En este sentido resultan más que pertinentes las palabras de Robert Darnton, en la introducción de su libro La matanza de gatos, al advertir que:

Debería ser posible que el historiador descubriera la dimensión social del pensamiento y que entendiera el sentido de los documentos relacionándolos con el mundo circundante de los significados, pasando del texto al contexto, y regresando de nuevo a éste hasta lograr encontrar una ruta en un mundo mental extraño (Darnton, 2002, p. 13).

Hacia 1909 habitaban en Las Flores más de 12.000 personas y las principales actividades económicas de la región eran la agricultura y ganadería. A pesar de haberse fundado en 1856, ya antes de 1860 el pueblo contaba con dos escuelas, una iglesia y un hospital. En 1864 se instaló el primer alumbrado público y en 1872, con la llegada del ferrocarril, la localidad cobró impulso y pronto se convirtió en un centro ferroviario, empalme de cuatro ramales de la empresa de capitales británicos Ferrocarril del Sud. Fomentadas por el ferrocarril se iniciaron varias obras de construcción de edificios públicos y privados y comenzaron a llegar inmigrantes que rápidamente poblaron la región y la marcaron con su impronta. Fue por entonces que surgieron diversas sociedades que buscaban mantener vivas las tradiciones de los que llegaban de tierras lejanas, así como brindar distinto tipo de asistencia a los socios en dificultades. También surgieron asociaciones en torno a distintos grupos de trabajadores, como el Club Social y Deportivo Ferroviario, fundado en 1903 por un grupo de empleados y obreros del ferrocarril, en el que se practicaban diversas actividades deportivas, especialmente, fútbol (Alvarez, Pagliere y Riquelme, 1999, 91). Debido al desarrollo alcanzado -Las Flores ya contaba con varias escuelas públicas, un hospital, una comisaría, una biblioteca, calles pavimentadas, una sucursal del Banco de la Provincia de Buenos Aires y un servicio de alumbrado eléctrico-, en enero de 1908 el pueblo fue declarado ciudad ${ }^{7}$.

Cabe destacar la fuerte impronta ferroviaria florense. En este empalme, entre 1905 y 1908, el Ferrocarril del Sud construyó un galpón de máquinas, segundo en importancia luego del de Remedios de Escalada, en el que se realizaba el mantenimiento y reparaciones del material rodante. En 1908 los maquinistas y foguistas agremiados en la sección florense de La Fraternidad decidieron abrir una escuela técnica, que resultó la primera del país y de Sudamérica, en donde los propios trabajadores capacitados impartirían lecciones a los foguistas que estuvieran listos para rendir examen de maquinista ${ }^{8}$. $\mathrm{Al}$ año siguiente, debido al aumento de tráfico, la estación del ferrocarril se trasladó a un lugar más abierto, en donde nuevas calles dieron origen al Barrio Ferroviario, signado por la presencia de los cientos de trabajadores que habitaban y circulaban en él. Asimismo, en torno a la estación se configuró un paseo del que disfrutaban cotidianamente viajantes y florenses. De este modo, hacia 1910 el ferrocarril constituía una figura aglutinante en Las Flores y marcaba la vida de sus pobladores, gran parte de los cuales trabajaba en él.

En la denuncia, Angélica contaba que vivía cerca de la estación, por lo que el contacto con los trabajadores ferroviarios debió haber sido algo cotidiano para ella y sus hijas, que habitaban a unos pocos metros del importante empalme, y quizá, como tantos otros pobladores, disfrutaban del paseo que este ofrecía. En este sentido, la estación ferroviaria era uno de los centros de actividad social de Las Flores -así como de tantas 
otras localidades-, un espacio de sociabilidad y encuentro. La estación podía ser un lugar de despedidas, pero también de encuentros, charlas informales, miradas y flirteos entre viajantes, visitantes, pobladores, $\mathrm{y}$ ferrocarrileros. Además, a principios del siglo pasado -y gran parte de las décadas subsiguientes - trabajar en el ferrocarril implicaba un prestigio social, sobre todo en determinados oficios calificados como el de maquinista y foguista, que brindaban un salario relativamente elevado, cierta estabilidad laboral y la posibilidad de hacer carrera (Palermo, 2016). En la memoria de algunos trabajadores, este prestigio se asociaba a ser "buenos candidatos" para las mujeres ${ }^{9}$. Por esto, es posible pensar que Bonifacio, foguista de una importante empresa y con posibilidades de convertirse en maquinista, fuera atractivo para una mujer como Angélica, migrante, abandonada por dos maridos, con cinco hijos, 38 años y quizá sin demasiadas posibilidades laborales y de subsistencia en un pueblo de campaña a principios del siglo XX. De hecho, ella misma había remarcado ante el comisario su sensación de haber perdido un marido joven y con empleo. ¿Cómo había vivido esta situación? ¿Qué emociones y sentimientos la atravesaron? ¿Qué elementos culturales y sociales moldearon sus experiencias afectivas?

\section{Afectos, EMOciones y SENTIMIENTOS EN LA DENUNCIA}

Angélica ocupa un lugar central en esta historia. Fue ella quien decidió presentarse ante la autoridad policial local y denunciar a Bonifacio, quien según su argumento se había aprovechado de ella y de sus hijas. Al narrar los hechos que la habían llevado a buscar justicia dejó entrever algunas de las expectativas que tenía al entablar su relación con el foguista. Explicaba que en un comienzo éste se había "portado bien”, era cariñoso y corría con los gastos de la casa. Al narrar el descubrimiento de que su hija Micaela estaba embarazada de Estrella y explicar el lío que esto había generado, Angélica expresó su malestar por haber perdido un marido joven y con empleo, pero mostró su resignación al afirmar que se había entregado a pensar que pasaría lo que tuviera que pasar. Contó también que habían surgido otros problemas cuando el cartero Gómez, al ver que ella estaba libre, comenzó a cortejarla. Al enterarse, Bonifacio le prohibió a Gómez acercarse a la casa esgrimiendo que mientras él sostuviera la familia, él mandaba. Al respecto, Angélica decía que entendía que Estrella tenía razón en parte, pero que ella también la tenía, porque él la había dejado por su hija y no podía impedirle buscar la felicidad en otros hombres. Contaba que, a pesar de sus protestas, Bonifacio había terminado por imponerse, y que ella le había hecho caso por comprender que el hombre no era malo del todo, a pesar de sus caprichos. Enseguida explicaba que después de tantas desilusiones, cuando pensaba renunciar a los hombres y buscar la felicidad en el nieto que estaba en camino, Bonifacio se dio a la fuga con su hija Dolores, a quien acusaba de sonsa por haberse ido con un "hombre asi".

A partir de las palabras de Angélica, trascriptas por el comisario, se pueden rastrear aspectos de su vida, así como algunas emociones y sentimientos que la situación le había generado. Para empezar, su presentación ante la autoridad policial dejaba expuesta su situación de precariedad económica y dependencia del ingreso de Bonifacio. En su declaración, la mujer se presentaba como viuda y entendía esta condición como la de haber perdido el marido, dado que en verdad no sabía nada del paradero de los hombres con quienes había formado pareja. Como fuera, ser viuda implicaba haber quedado sola a cargo de sus hijos. También, es importante tener en cuenta la condición de migrante de Angélica. Es sabido que entre los hogares criollos la jefatura femenina era algo común, a diferencia de lo que sucedía con los extranjeros (Míguez, 1999, 24), pero, en este caso, el haberse desplazado de su Santiago natal -su hija Dolores, de 15 años, había nacido en Santiago, por ende la migración fue posterior- pudo haber jugado un rol en el impedimento de Angélica de sostener el hogar en Las Flores. Angélica no hizo referencia a ningún trabajo o profesión, y aunque podía laborar o combinar trabajo con otras formas de subsistencia, queda claro que Estrella era el sostén del hogar, compuesto por ella, las dos hijas que había tenido con su primera pareja, y tres hijos más, fruto de su segunda relación. De hecho, el reclamo tenía que ver más con la sobrevivencia de la familia que con lo amoroso o afectivo; era la misma Angélica quien aclaraba que después de lo ocurrido era muy difícil "conseguir" otro hombre que se quisiera 
hacer cargo de la familia, por lo que su presentación en la comisaría era algo así como un último recurso. Al fin y al cabo, lo que estaba en juego no era tanto la expectativa de Angélica de formar pareja, sino la de garantizar la subsistencia de los suyos. En este sentido, según señaló la denunciante, antes de fugarse, Estrella había mostrado ser cariñoso y -lo que parecía aún más importante- poder correr con los gastos de la casa. Al seguir el relato de Angélica, se puede pensar que él mismo aceptaba el rol y las prerrogativas que otorgaba el ser el varón proveedor -como ser quien tomaba las decisiones- al decirle al cartero que era él quien mandaba, dado que él mantenía a la familia. En la declaración de Angélica, asimismo, se vislumbra cierta valoración sobre su hija Dolores, de quien dijo que era "medio sonsa" por haberse ido con un hombre como Bonifacio. En contraposición con la actitud de Dolores, al narrar las circunstancias en que conoció a Estrella, Angélica se colocó ella misma en el lugar de una mujer prevenida, desconfiada y con recaudos que, debido a sus fallidas experiencias con los hombres, no aceptaba matrimonio con alguien a quien conociera poco. Por supuesto que no hay que perder de vista que Angélica estaba contando al comisario la mejor historia posible en pos de conseguir que éste atendiera su reclamo. Respecto a los conceptos de "marido" y "casamiento", es sugerente pensar que más que referir a la unión legal o sacramento podían simplemente aludir a una pareja constituida. De hecho, varias veces Angélica habló de Bonifacio como un "marido" (el seductor era su propio marido, quedando como marido de Micaela, perdía un marido joven), y al informar que se había casado dos veces es factible que quisiera decir que se había amancebado y formado familia dos veces, sobre todo si se considera que las uniones de hecho estaban bastante extendidas entre la población nativa de la época (Barrancos, 2000; Bjerg, 2005-2006; Moreno, 2004).

Asimismo, al especificar su pedido, Angélica dejó al descubierto algo sobre lo que entendía como el "honor de la familia”. Para salvar el honor familiar, que evidentemente estaba en peligro a partir de lo sucedido, la mujer creía necesario que Bonifacio se casara con alguna de sus hijas o con ella. Si se considera el honor como un atributo y código de regulación social cuyo significado ha ido cambiando en distintos lugares y momentos históricos -algo en permanente negociación, que podía ser disputado y resignificado por distintos sectores sociales y que implicaba distintas cuestiones para varones y mujeres (Chambers, 2003)-, se ve que el pedido de Angélica dice algo sobre sus propias nociones sobre el honor y las normas de conducta aceptadas o esperables para merecer respeto. También dice algo sobre sus propias nociones sobre lo "justo", encarnadas en este caso por el pedido de que Bonifacio volviera y decidiera con quién de las mujeres casarse. Pero, ¿qué tenían para contar Bonifacio y Dolores sobre esta misma historia? ¿Cómo habían vivido ellos esta situación? ¿Qué emociones y sentimientos los atravesaron?

Al dar por terminada la denuncia, y luego de oír el relato de la mujer, el comisario Marcos Andrade ordenó al sargento Troncoso pedir prestados dos caballos para salir a buscar a la pareja fugada y llevarla a la comisaría. Cinco días después, el 20 de enero de 1909, con la pareja ya encontrada, resolvió que Bonifacio y Dolores se presentaran ante él para que pudiera tomarles declaración. Dolores fue la primera en declarar; se comprometió a contar todo lo sucedido y a responder las preguntas formuladas por Andrade. Informó llamarse Dolores Carreño, tener quince años de edad, ser santiagueña "como toda la familia”, no saber escribir ni leer, pero sí firmar. El comisario aclaraba tener la obligación de dejar constancia de que la muchacha estaba bien desarrollada y de que a pesar de su edad ya era "mujercita y buena". Enseguida, y ante la pregunta sobre si sabía por qué había caído presa, Dolores afirmaba estar al tanto que la habían tomado por haberse fugado con Bonifacio. Preguntada sobre qué había pasado, contó que ella lo había querido a Estrella desde que lo conoció y que él la había correspondido enseguida, pero como era algo chica todavía, y él tenía "compromisos" con su madre y su hermana, habían resuelto esperar. Agregaba que hacía una semana (para el momento de la fuga más o menos) Estrella la había probado como mujer y estaba muy conforme con ella. Ante la pregunta del comisario, Dolores afirmaba que no estaba arrepentida de nada, que Estrella ya había cumplido con su madre y su hermana, y que bastante ya había tenido que esperar mientras él las "atendía”, por lo que era justo que ahora se lo dejaran a ella, aunque fuera por un tiempo, para que Bonifacio pudiera conocerla mejor y después eligiera con quién quedarse. Agregaba que su madre había hecho la denuncia por despecho y que prefería no 
decir cosas peores para que la gente no hablara. En sus palabras se advierte su concepción de que la decisión final la tenía él; es decir, él era quien iba a elegir con quién de las tres quedarse, pero por eso ahora le tocaba a ella hacerse conocer. Si bien Dolores afirmaba no estar arrepentida, en sus últimas palabras, al igual que Angélica al hablar de salvar el honor de la familia, se percibe su preocupación y la importancia atribuida al "qué dirán". Evidentemente, la opinión pública, sobre todo en un pueblo en donde ser anónimo era más difícil que en una ciudad en la misma época, podía dañar y arruinar la reputación de las personas y familias, y esto era algo de lo que estaban conscientes tanto Angélica como su hija.

Al finalizar con las preguntas a Dolores, el comisario hizo pasar a Bonifacio para comenzar con la interrogación. Éste informó llamarse Bonifacio Estrella, ser santafecino, de veinticinco años de edad, casado, empleado del Ferrocarril del Sud, y no tener antecedentes ni haber estado nunca preso. Ante la pregunta del comisario, contestó que sabía que lo habían agarrado por lo que había hecho y que se ponía a disposición de la autoridad. Explicaba que se había fugado con Dolores porque la quería y que ella lo correspondía. Preguntado por su relación con Micaela, respondió que era verdad que antes vivía con ella y que la muchacha iba a tener un hijo suyo, que también la quería mucho dado que era buena y que ella no lo hubiera metido en líos de no ser por la madre, quien según él había hecho el barullo, enojada porque al principio vivía con ella y luego la dejó. Ante la pregunta de si había prometido casamiento a alguna de estas mujeres, explicó que no, que ya estaba casado con Rimunda Bustos, pero que si la mujer se moría pronto "como tiene esperanza", porque hacía mucho que estaba enferma, entonces tal vez podría "cumplir" aunque fuera con Dolores, pero con "la vieja” nunca. Parece que esta declaración sorprendió al comisario, quien enseguida inquirió sobre si su esposa sabía de las relaciones con las Carreño. Estrella contestó que sí y aclaró que como él cumplía con las obligaciones y no tenía vicios, "antes que ande chupando y jugando por los boliches", su mujer le permitía tener esas "distracciones" afuera de la casa, pues era sensata y comprendía que, dado que ella estaba enferma y que él era un hombre sano y joven, tenía que tener sus tentaciones.

A partir de la declaración de Estrella salen a la luz algunas cuestiones que permiten un acercamiento a su universo emocional y al tipo de vínculos establecidos entre él y las varias mujeres presentes en su vida. En primer lugar, afirmaba haberse fugado con Dolores porque la quería y era correspondido por ella, en consonancia con lo dicho por la muchacha al declarar. De Micaela decía que también la quería mucho y que era buena. En su interpretación, era Angélica, a quien se refería despectivamente como "la vieja", la que había comenzado el lío enojada con él por haberla dejado. En el modo de referirse a Angélica se percibe cierto enojo de Bonifacio con la mujer por haberlo denunciado y también algo sobre el modo en que la diferencia etaria entró en juego en este caso. La mujer tenía treinta y ocho años, mientras que Estrella tenía veinticinco, una diferencia de edad que a principios del siglo XX implicaba determinadas cuestiones diferenciales para varones y mujeres: con casi cuarenta años una mujer podía ser considerada una anciana, mientras que con sus veinticinco años Bonifacio aún era un joven con tentaciones que debían ser satisfechas. Por otro lado, resulta llamativa -inclusive para un observador contemporáneo como el comisario- la libertad con la que contaba Bonifacio para pasar el tiempo lejos de su esposa. Según su relato, ella estaba al tanto de sus "distracciones" y las avalaba. Lo que no queda claro es si Angélica y sus hijas estaban enteradas de la situación marital de Bonifacio. Se puede pensar que no, ya que el pedido de la denunciante residía básicamente en que Estrella eligiera con quién casarse, lo que indica que ella no sabía que él no podría contraer matrimonio, al menos hasta que su esposa muriera, o quizá sabía, y simplemente utilizaba el concepto de "casamiento" para significar una unión de hecho. Según el razonamiento de Bonifacio, su conducta estaba justificada dado que él era un hombre sano y joven que tenía tentaciones que su esposa no podía satisfacer por estar enferma. En sus palabras se aprecia también que el hecho de pasar el tiempo en los boliches bebiendo y jugando era valorado como algo negativo, al menos más negativo que hacer vida marital con mujeres que no fueran la propia esposa ${ }^{10}$. Al respecto, también es interesante tener en cuenta la relativa libertad de movimiento de la que probablemente gozaba Bonifacio al desempeñarse como foguista ferroviario. Tanto los foguistas como los maquinistas de los ferrocarriles estaban acostumbrados a pasar períodos de tiempo más o menos prolongados lejos de sus 
hogares y familias, y quizá esta circunstancia le permitía a Bonifacio excusar ausencias ante a su esposa y ante las Carreño. Probablemente, los desplazamientos continuos implicaban para los trabajadores una relativa independencia y autonomía respecto al ámbito doméstico, lo que pudo haber conformado una identidad masculina particular y formas específicas de construir y entablar lazos afectivos. A su vez, desde mediados del siglo XIX era común entre los pobladores de la zona pampeana y distintas zonas del interior que los varones - gran parte de los cuales eran peones o jornaleros- tuvieran una alta movilidad geográfica, motivada la mayoría de las veces por la búsqueda de trabajo. Muchos de los que se iban no volvían al hogar, por lo que otros podían llegar a ocupar sus lugares (Moreno, 2004, 111). Sin ir más lejos, esto había sucedido con las parejas anteriores de Angélica, Francisco y Casimiro, padres de sus hijos. Muchos varones aprovechaban esta movilidad para mantener varias relaciones con distintas mujeres y vivir amancebados con mujeres que no eran sus legítimas esposas. Al mismo tiempo, las mujeres podían hacer lo propio si eran abandonadas por sus maridos. Estas prácticas estaban bastante generalizadas, y, por ende, eran naturalizadas por la población de las zonas de campaña, lo que, como han señalado varios autores (Bjerg, 2005-2006, p. 52; Míguez, 1999, p. 21), debe ser relacionado con la escasa influencia de la Iglesia Católica y del Estado sobre las prácticas familiares en estas regiones durante buena parte del siglo XIX. De hecho, si no conseguían formar una familia estable, para escapar de una vida mísera, las mujeres de las clases populares tomaban la iniciativa para crear una pareja sobre bases explícitas, casi contractuales (Moreno, 2004, p. 116). De todos modos, y como deja en evidencia el caso de Angélica, eran ellas quienes tenían las de perder, sobre todo si tenían hijos, dado que quedaban como únicas responsables de su crianza. Eran así el “eslabón más débil en la cadena de conflictos amorosos”, ya que les resultaba sumamente difícil reclamar algo de los varones que las abandonaban, inclusive en canales formales como la Justicia (Moreno, 2004, p. 119) ${ }^{11}$.

Hacia el final de su declaración, Bonifacio dejó entrever algo sobre sus nociones sobre lo justo y lo esperable en su vínculo con Angélica y sus hijas, y sobre las prerrogativas de las que gozaba -o consideraba que debía gozar- por ser el varón sostén del hogar. Aclaraba no sentirse culpable de nada y decía que si bien era verdad que había hecho vida marital con las tres mujeres, era él quien con su trabajo sostenía a toda la familia, y que entonces era "justo" que ellas lo retribuyeran de alguna forma. Evidentemente, más allá de que las mujeres le dieran casa y de que seguramente se ocuparan de tareas del hogar -como cocinar, lavar y remendar ropa-, el sexo y el afecto formaban parte de las obligaciones domésticas que Bonifacio esperaba de ellas por ser el varón proveedor.

\section{EL ROL DEL COMISARIO}

Además de contener la denuncia de Angélica y las declaraciones de Dolores y Bonifacio, el sumario abierto por la autoridad policial incluye las resoluciones y ciertas apreciaciones del comisario de Las Flores, Marcos Andrade. Como advierte María Bjerg (2018) en un artículo reciente, las emociones eran experimentadas y gestionadas por todos los involucrados en un proceso judicial, no solo por querellantes, imputados y testigos. Abogados, fiscales y jueces podían entremezclar criterios de racionalidad con sentimientos y condenas morales, y muchas veces se generaban puntos de convergencia entre las partes. De este modo, varones demandantes o denunciados y funcionarios y agentes judiciales podían expresar nociones comunes sobre la obediencia, el honor y el lugar de las mujeres y, como se verá -y aunque el caso aquí trabajado no constituye un proceso judicial sino tan solo una denuncia en la comisaría-, este fue el caso de la autoridad policial de Las Flores y el del acusado.

Luego de escuchar y asentar la denuncia de Angélica, Andrade resolvió dar orden de buscar a la pareja fugada. Una vez que esta se presentó a prestar declaración, el comisario, además de dejar constancia de algunas apreciaciones personales (como que Dolores estaba bien desarrollada y ya era una "buena mujercita", y que Bonifacio era un hombre guapo), formuló ciertas preguntas con las que fue guiando la narración de los sujetos involucrados, tal como había hecho al escuchar el relato de Angélica. Pero es hacia el final del sumario en 
donde expresó sus valoraciones sobre el caso. Al finalizar la toma de declaraciones, el comisario resolvió largar a Dolores y a Bonifacio, por considerar que la muchacha se había fugado por gusto con Estrella y que entre ellos se querían. Agregaba que viviendo juntos no le habían hecho mal a nadie, y que, si bien Bonifacio era casado, su mujer estaba enferma y no le servía "para nada". Igualmente, para dejar su conciencia tranquila, según él mismo explicaba, decidió mandarle el sumario a Liberato Monje, jefe de policía del departamento, en Mercedes, para que éste lo revisara y dijera si estaba bien o no lo resuelto por él. En la nota dirigida a Monje, explicaba que como le parecía que a Bonifacio le gustaba más Dolores, que era "la mejor de las tres", había resuelto dejarlos en libertad porque creía que ellos [Andrade y Monje], que alguna vez también habían sido "potros", no tenían derecho de estropear la felicidad de nadie. Agregaba que, en su opinión, "la vieja" [Angélica] había hecho la denuncia por despecho, después de que Bonifacio la hubiera "cambiado" por sus hijas. Por esa razón, explicaba, le parecía que al dejarlos en libertad se volverían a arreglar entre ellos, y que, si bien era cierto que Estrella había sido el marido de todas, él les daba de comer; entonces no era justo que las tres comieran de sus costillas y "de arriba”. Finalizaba diciendo que, si lo metían preso a Bonifacio, ellas seguramente se arreglarían con el primero que les parara la olla y que por eso consideraba mejor dejar las cosas como estaban y que ellas continuaran viviendo con Estrella y él "cuidando la decencia de las casas".

Varias cosas interesantes salen a la luz a partir de las explicaciones del comisario. Al igual que Estrella al revelar su situación marital, Andrade consideraba que una esposa enferma no servía "para nada" y por eso mismo avalaba la conducta de Bonifacio. También, en su opinión, Dolores era "la mejor" de las tres mujeres (quizá sus quince años coadyuvaban a su percepción) y Angélica, nuevamente adjetivada como "la vieja", había denunciado a Estrella por despecho, idea que ya había sido expresada por Dolores y por Bonifacio. Resulta sugestivo advertir la idea del sentimiento de despecho adjudicado a Angélica para explicar su accionar. En este sentido, para aquellos otros contemporáneos involucrados en el caso, el reclamo de la mujer no tenía que ver con conseguir algo que ella consideraba justo, sino que estaba directamente ligado a una voluntad de venganza tras haber sido dejada por Bonifacio. Finalmente, para justificar su decisión de liberar a la pareja, el comisario utilizaba el argumento esgrimido por Bonifacio: como él les daba de comer a todas, era justo que ellas le dieran algo a cambio. Nuevamente aquí aparece la noción de que ser el varón proveedor otorgaba ciertas prerrogativas. Tomar las decisiones de la casa y ser satisfecho como varón con tentaciones eran evidentemente algunas de ellas. En la última parte de su exposición, se advierte otra de las valoraciones de Andrade. Al afirmar que, de continuar viviendo con las mujeres, Estrella cuidaría la decencia de las casas se aprecia cómo el comisario creía que la presencia del varón en la casa coadyuvaba a que la manera de vivir de Angélica y sus hijas se ajustara a lo esperable, a las buenas costumbres y normas sociales aceptadas. En un sentido similar se había expresado Angélica al afirmar que ella podría casarse con él con tal de salvar el honor familiar.

Por su parte, en la nota de respuesta remitida al comisario, el jefe de policía informaba que aprobaba el procedimiento realizado por Andrade y compartía algunas de sus valoraciones. Expresaba que tanto la denunciante como sus dos hijas eran mujeres grandes "en estado de merecer", y que, por ende, ya debían saber lo que les convenía. En su opinión, las tres habían vivido a gusto con el acusado mientras él les daba de comer y solo se quejaban cuando éste, "cansado de sostener la familia", las abandonaba decidiendo quedarse con una sola. Por ello, entendía que el abuso era más de ellas que de él.

\section{Pensar los afectos En El MUNDo Del trabajo}

A partir del análisis de la denuncia surgieron algunas preguntas e ideas sobre los sentimientos, emociones, afectos, vínculos, valores, normas esperables de conducta que experimentaron un grupo de sujetos pertenecientes a los sectores trabajadores, así como sobre las tensiones y conflictos que podían generarse en torno a estas cuestiones. ¿Qué puede aportar este caso particular al conocimiento de la vida de los trabajadores ferroviarios? ¿Qué sabemos sobre los sentimientos y cultura afectiva de los trabajadores? ¿Qué potencial tiene 
la pregunta por los afectos para pensar el mundo del trabajo? ¿Cómo se han abordado los sentimientos y las emociones -si es que han sido abordados- en este campo historiográfico?

El tema de la cultura afectiva y emocional de las clases trabajadoras es una problemática histórica aun poco explorada en la Argentina. De forma particular, dentro de la historia social del trabajo han sido pocos los intentos y el interés por indagar la dimensión emocional y sentimental de los trabajadores. De cualquier manera, esto no significa que el conocimiento sobre la temática sea nulo, o que investigaciones que tuvieron lugar con anterioridad a la conformación de un campo de estudio particular -como es el de las emociones, afectos y sentimientos- no se hayan preguntado por esta dimensión de la vida de los trabajadores. Pero lo cierto es que, si se tiene en cuenta la producción e interés creciente de distintas disciplinas en este campo de investigación, se ve que éste es más incipiente dentro de la historia en general y de la historia social del trabajo en particular. Por su parte, tanto la sociología como la antropología, así como los estudios de género, han experimentado un fuerte crecimiento de la producción teórica y de las investigaciones que incorporaron esta dimensión a sus análisis (Abu-Lughod y Lutz, 1990; Fernández Álvarez, 2011; Goodwin, Jasper y Polleta, 2001; Illouz, 2007, 2009). De hecho, desde hace algunos años hay quienes hablan del "giro afectivo" para dar cuenta del empuje, auge y creciente atención a los afectos y las emociones desde las ciencias sociales y las humanidades (Abramowski y Canevaro, 2017; Arfuch, 2016; Lara y Domínguez, 2013; Macón y Solana, 2015). Si bien el "giro" no parece haber sido tal en la disciplina histórica, dentro de la cual surgieron preguntas y debates en torno a si existía y era posible una historia de las emociones (Burke, 2005; Rosenwein, 2002), distintos estudios han indagado en este terreno, aunque desde diversas perspectivas y enfoques teóricometodológicos. Algunos historiadores se han preguntado por cómo hacer una historia de las emociones "desde abajo" (Langhamer, 2013), engenerizada (Candau, 2016; Frevert, 2011, Roper, 2005), que considere su carácter cultural y social (Almeida, 2017), y han avanzado en este sentido ${ }^{12}$.

Uno de los principales desafíos señalados por quienes han reflexionado sobre la posibilidad de historizar los afectos tiene que ver con la supuesta escasez de fuentes que permitirían rastrear el universo de emociones y sentimientos de quienes formaron parte de la clase trabajadora. En este sentido, muchos de los trabajos interesados en recuperar esta dimensión concentraron su atención en los sectores medios y altos (Barrán, 2001; Mayo, 2004; Smith-Rosenberg, 1975; Zaragoza Bernal, 2013), en gran parte debido a la mayor disponibilidad de documentos utilizados como puerta de entrada a la cultura afectiva, como diarios íntimos y cartas. Pero más allá de lo esquivas y fragmentarias que puedan resultar las fuentes y huellas del pasado, distintas investigaciones, con variadas preguntas, inquietudes y objetivos, lograron recuperar experiencias y trazos de la educación sentimental de las clases populares y los trabajadores (Baily, 1988; Barrancos, 2008 y 2014a; Bjerg, 2018; Fansworth, 1997; Lobato, 2011a, 2014 y 2017; Sarlo, 1985). A partir de fuentes variadas como correspondencia, testimonios orales, registros de personal, juicios, prensa periódica, folletines e imágenes, estos estudios muestran que los documentos no dicen nada por sí mismos, y que son las preguntas, lecturas e interpretaciones de los historiadores y de las historiadoras las que intervienen en la aproximación al pasado. En este sentido, queda claro que la escasez o silencios de las fuentes no alcanzan para excusar la poca preocupación por la dimensión afectiva y emocional, ya que es posible sortear estas dificultades a partir de lecturas en clave afectiva, atentas y a contrapelo ${ }^{13}$, de documentos largamente conocidos y abordados por la historiografía de los trabajadores.

Otra posible explicación de la relativa escasez de investigaciones sobre sentimientos, afectos y emociones en el campo de la historia de los trabajadores y de las trabajadoras podría estar relacionada con que el tema no está del todo legitimado; es pensado como un aspecto menor o subsidiario en relación a otras temáticas consideradas más importantes cuando no centrales ${ }^{14}$. Igualmente, existen diversos análisis que incluyen de manera más o menos explícita- esta dimensión, sobre todo entre quienes realizan una historia social con perspectiva de género. Muchos de los estudios que desde mediados de 1980 formaron parte de la renovación historiográfica del campo de la historia de los trabajadores comenzaron a incluir preguntas sobre la cultura obrera, y la convirtieron, en algunos casos, en el eje central de la investigación (Armus, 1990; Barrancos, 1991 
y 1993; Falcón, 1986; Lobato, 1990 y 2001; Suriano, 1983 y 2011). Al partir de la historia social y cultural y críticos de una historiografía política que había centrado su atención en las organizaciones obreras y en las corrientes políticas e ideológicas a ellas vinculadas, estas investigaciones funcionaron como una especie de puntapié a partir del cual el análisis sobre la vida obrera se amplió a la vida cotidiana, la comunidad, el tiempo libre, las costumbres y la participación de las mujeres en los trabajos y protestas, entre otras problemáticas (Andújar, 2015; Lobato, 2007, Palermo, 2007). Estos estudios enriquecieron el conocimiento sobre las experiencias de los trabajadores y de las trabajadoras dentro y fuera del espacio de la explotación laboral, y acabaron con la idea de la neutralidad de género en el mundo del trabajo ${ }^{15}$. A su vez, estas nuevas maneras de concebir y comprender la historia obrera suscitaron nuevas preguntas e intereses; desplazaron el análisis hacia otros terrenos y configuraron nuevos campos temáticos como la sexualidad, los festejos y rituales, las prácticas deportivas o la sociabilidad (Barrancos, 1999; Camarero, 2007; D’Uva y Palermo, 2015; Lobato, 2011 b y 2014). Sin dudas, al indagar otras instancias más allá de los lugares de trabajo, organizaciones sindicales y políticas, estos trabajos abrieron un camino para pensar la cultura afectiva de los trabajadores.

En el afán de explicar o reflexionar sobre la poca atención que la historiografía del trabajo dedicó a la dimensión afectiva y emocional, a pesar de la expansión y revitalización que ha experimentado este campo en los últimos años, podría señalarse que el tópico quedó relegado de muchos estudios al ser considerado propio del ámbito privado e íntimo de los trabajadores. Pero, transcurridas más de tres décadas desde aquellos primeros estudios de historia social que renovaron el campo, y gracias a las numerosas investigaciones que con inquietudes feministas y desde la perspectiva género contribuyeron a desmontar la noción de "esfera privada" -asociada a lo doméstico y femenino-, como contraposición de una "esfera pública" y masculina, ya nadie podría ampararse en semejante concepción. Actualmente, nuevas líneas de análisis, alejadas de aquella construcción dicotómica entre público y privado, indagan temas como el trabajo realizado en el interior del hogar, el servicio doméstico, los vínculos entre trabajo y pobreza, el trabajo sexual y los llamados trabajos "reproductivos" y de cuidado llevados a cabo por mujeres (Allemandi, 2017; Mitidieri, 2018; Pérez, 2014 y 2017; Pita, 2018, Schettini, 2016). En conjunto, estas investigaciones invitan a reflexionar en los sentidos históricos del trabajo, engenerizar espacios considerados neutrales en este sentido, y ver cómo en ámbitos considerados "privados" o "domésticos" también operaron construcciones políticas, sociales y económicas que modelaron las experiencias de los trabajadores y trabajadoras.

A pesar de los obstáculos señalados, y desde hace más de una década, distintas investigaciones se interesaron en recuperar y problematizar la dimensión afectiva y emocional de las experiencias de la clase trabajadora. Varias autoras y autores indagaron en las relaciones afectivas, sexuales, familiares, de amistad y camaradería que entablaron los y las trabajadoras, y en algunos casos se detuvieron en aquellas que se corrieron de la norma (Acha y Ben, 2004; Acha, 2007; Barrancos, 2014a y 2014b; Ben, 2014; Fiorucci, 2013; Lobato, 2011

y 2014; Simonetto, 2017) ${ }^{16}$. También, aunque no fuera el eje del análisis, algunos estudios sobre la familia y las mujeres en la Argentina indagaron aspectos relacionados con las experiencias y dinámicas familiares de los sectores populares en distintos momentos históricos, y echaron luz sobre sus valores, normas de conducta y experiencias emocionales y afectivas (Bjerg, 2005-2006 y 2017; Gil Lozano, Pita, Ini, 2000; Míguez, 1999; Moreno, 2004; Quinteros y Cowen, 2018; Rodríguez Molas, 1984). Cada una de estas investigaciones aporta a la historización de las emociones al desencializar los afectos e indagar en su construcción social, más que pensarlos como experiencias individuales. Gracias a ellas, sabemos más sobre las formas en que trabajadores y trabajadoras se relacionaron, compartieron su tiempo y tejieron vínculos afectivos.

\section{A MODO DE CIERRE}

La historia de Angélica, sus hijas y Bonifacio invita a pensar en otros modelos familiares y dinámicas afectivas que se distancian de forma significativa del rol de jefe de familia y padre responsable que estaba presente en muchos trabajadores de los ferrocarriles a principios del siglo XX (Palermo, 2007, 2013, 2016). 
Prestar atención a las emociones y vínculos afectivos permitió advertir el rol que estos jugaron en la articulación de nociones sobre lo justo y en la puesta en práctica de ciertas estrategias de negociación, agencia, resistencia y sobrevivencia. En este sentido, Angélica supo aprovechar la circunstancia e intervenir activamente para modificar su realidad presentándose ante la autoridad policial para narrar lo sucedido y reclamar un resarcimiento de acuerdo a lo que ella consideraba como justo. En sus respectivas declaraciones, tanto ella como Dolores y Bonifacio dejaron al descubierto sentimientos y emociones que explicaban o excusaban su manera de actuar. Seguramente queda mucho para seguir pensando, dado que el potencial de la denuncia para indagar y problematizar la dimensión afectiva de la vida de los trabajadores no se agota en el análisis aquí realizado. De lo que no quedan dudas es de que ya no podemos desconocer que los afectos, sentimientos y emociones jugaron un rol en los espacios de trabajo y sociabilidad, en las instancias de acción colectiva, en las comunidades laborales y barriales, en los vínculos entablados entre los trabajadores y trabajadoras. Lejos de ser un dato de color, emociones y afectos resultan una dimensión constitutiva de la experiencia obrera que aún espera a ser abordada de forma más sistemática por la historia social.

\section{REFERENCIAS}

Abramowski, A., y Canevaro, S. (comp.) (2017). Pensar los afectos. Aproximaciones desde las ciencias sociales y las humanidades. Los Polvorines: UNGS.

Abu-Lughod, L. \& Lutz, C. (1990). Introduction: emotion, discourse, and the politics of everyday life. In L. AbuLughod \& C. Lutz (comps.), Language and politcs of emotion (pp. 1-23). Cambridge: Cambridge University Press.

Acha, O., y Ben, P. (2004). Amorales, patoteros, chongos y pitucos. La homosexualidad masculina durante el primer peronismo (Buenos Aires, 1943-1955). Trabajos y Comunicaciones Segunda Época, 30-31, 217-260. Recuperado de http://www.memoria.fahce.unlp.edu.ar/art_revistas/pr.316/pr.316.pdf.

Acha, O. (2007). Cartas de amor en la Argentina peronista: construcciones epistolares del sí mismo, del sentimiento y del lazo político populista. Nuevo Mundo Mundos Nuevos. http://10.4000/nuevomundo.12272

Albornoz Vásquez, M. E. (dir.) (2016). Sentimientos y Justicia. Coordenadas emotivas en la factura de experiencias judiciales. Chile 1650-1990. Santiago de Chile: Acto Editores.

Allemandi, C. (2017). Sirvientes, Criados y Nodrizas: Una historia del servicio doméstico en la ciudad de Buenos Aires (fines del Siglo XIX y principios del XX). Buenos Aires: Teseo/Universidad de San Andrés.

Alvarez, N., Pagliere, L., y Riquelme, G. (1999). El camino de Las Flores, 1856-1998. Contraflor Producciones.

Andújar, A. (2015). Comunidad obrera, género y políticas asistenciales: Comodoro Rivadavia, 1922-1932. Archivos, 7, 59-78. Recuperado de http://www.archivosrevista.com.ar.cal.toservers.com/contenido/wp-content/upload s/2015/08/Andujar.pdf

Andújar, A. (2018). Historia social del trabajo y género en la Argentina del siglo XX: balance y perspectivas. REFA, 8 , 43-59. Recuperado de http://www.refa.org.ar/file.php?tipo=Contenido\&id=172

Arfuch, L. (2016). El 'giro afectivo'. Emociones, subjetividad y política. deSignis, 24, 245-254. Recuperado de http:/ /www.designisfels.net/publicaciones/revistas/24.pdf

Armus, D. (comp.) (1990). Mundo urbano y cultura popular. Buenos Aires: Sudamericana.

Baily, S. (1988). One Family, Two Worlds: An Italian Family's Correspondence Across the Atlantic, 1901-1922. New Brunswick: Rutgers University Press.

Barclay, K. (2017). Performing Emotions and Reading the Male Body in Irish Courts, 1800-1845. Journal of Social History, 51(3), 293-312. https://doi.org/10.1093/jsh/shx017

Barrán, J. P. (2001). Amor y transgresión en Montevideo: 1919-1931. Montevideo: Ediciones de la Banda Oriental.

Barrancos, D. (1991). Cultura, educación y trabajadores 1890-1930. Buenos Aires: CEAL.

Barrancos, D. (1993). Historia y Género. Buenos Aires: CEAL. 
Barrancos, D. (1999). Moral sexual, sexualidad y mujeres trabajadoras en el período de entreguerras. En F. Devoto y M. Madero (dir), Historia de la vida privada en la Argentina. (Tomo 3, pp. 194-220). Buenos Aires: Taurus.

Barrancos, D. (2000). La vida cotidiana. En M. Lobato (dir), Nueva Historia Argentina (Tomo V, pp. 553-599). Buenos Aires: Sudamericana.

Barrancos, D. (2008). La puñalada de Amelia (o cómo se extinguió la discriminación de las mujeres casadas del servicio telefónico en la Argentina). Trabajos y Comunicaciones, 8(34). Recuperado de http://www.memoria.fahce.unl p.edu.ar/art_revistas/pr.3726/pr.3726.pdf

Barrancos, D. (2014a). Sentidos, sentimientos y sensibilidades (1880-1930). Revista Latinoamericana de Estudios sobre Cuerpos, Emociones y Sociedad, 15, 27-39. Recuperado de http://www.relaces.com.ar/index.php/relaces/article $/$ view/331/213

Barrancos, D. (2014b). Casamiento oriental: matrimonio de argentinos y de residentes en la Argentina en la República Oriental del Uruguay en las décadas de 1920 y 1930. En D. Barrancos, D. Guy y A. Valobra (eds.), Moralidades y comportamientos sexuales: Argentina 1880-2011 (pp. 175-193). Buenos Aires: Biblos.

Ben, P. (2014). La ciudad del pecado. Moral sexual de las clases populares. En D. Barrancos, D. Guy y A. Valobra (eds.), Moralidades y comportamientos sexuales: Argentina 1880-2011 (pp. 95-113). Buenos Aires: Biblos.

Bergallo, J. R. (1943). Cuentos del Juzgado. Retrato del norte santafesino. Buenos Aires: Ediciones Anaconda.

Bjerg, M. (2005-2006). Un caleidoscopio social. Familia, parentesco y mestizaje en la campaña de Buenos Aires en el siglo XIX. Quinto Sol, 9-10, 47-72. Recuperado de https://cerac.unlpam.edu.ar/index.php/quintosol/article/v iew/707

Bjerg, M. (2017). Emociones, inmigración y familia en la Argentina de fines del siglo XIX. Anuario IEHS, 32(2), 7-26. Recuperado de http://anuarioiehs.unicen.edu.ar/Files/2017\%202/01\%20Anuario\%20IEHS\%2032(2)\%20a.B jerg.pdf

Bjerg, M. (2018). Matrimonios malogrados y pasiones iracundas: inmigrantes en la justicia criminal. Ciudad de Buenos Aires, 1900-1920. Revista Historia y Justicia, 11, 42-67. Recuperado de http://revista.historiayjusticia.org/wp-c ontent/uploads/2018/11/d-RHyJ-11-Dossier-BJERG-OK.pdf

Bjerg, M. (2019). Una genealogía de la historia de las emociones. Quinto Sol, 23(1), 1-20. Recuperado de https://cer ac.unlpam.edu.ar/index.php/quintosol/article/view/2372/3707

Bock, G. (1991). La historia de las mujeres y la historia del género: Aspectos de un debate internacional. Historia Social, 9, 55-77. Recuperado de http://www.historiasocial.es/wordpress/la-revista/

Burke, P. (2005). Is There a Cultural History of the Emotions? In P. Gouk y H. Hills (eds.), Representing Emotions: New Connections in the Histories of Art, Music and Medicine (pp. 35-48). Aldershot: Ashgate.

Candau, M. L. (2016). Las mujeres y las emociones en Europa y América. Siglos XVII y XIX. Santander: Editorial de la Universidad de Cantabria.

Camarero, H. (2007). A la conquista de la clase obrera. Los comunistas y el mundo del trabajo en la Argentina, 1920-1935. Buenos Aires: Siglo XXI.

Chambers, S. (2003). De súbditos a ciudadanos: honor, género y política en Arequipa, 1780-1854. Lima: Red para el desarrollo de las Ciencias Sociales en el Perú.

D’ Uva, F., y Palermo, S. A. (2015). Vida sindical y sociabilidades masculinas: los trabajadores ferroviarios en la Argentina de principios del siglo XX. Archivos, IV(7), 37-58. Recuperado de http://www.archivosrevista.com.a r.cal.toservers.com/contenido/wp-content/uploads/2015/08/DUva-Palermo.pdf

Darnton, R. (2002) [1984]. La gran matanza de gatos y otros episodios de la Historia cultural francesa. México, D. F.: Fondo de Cultura Económica.

De Almeida, A. R. (2017). Perspetiva sobre a história das emoções. O casamento de D. Leonor de Portugal com o imperador Frederico III (1452). En A. Rodrigues, M. Santos Silva y A. Leal de Faria (coord.), Casamentos da Familia Real Portuguesa (pp. 253-287). Lisboa: Círculo de Leitores.

Falcón, R. (1986). El mundo del trabajo urbano (1890-1914). Buenos Aires: CEAL.

Farge, A. (1991). La atracción del archivo. Valencia: Ed. Alfons el Magnánim. 
Farnsworth-Alvear, A. (1997). Talking, Fighting, Flirting: Workers' Sociability in Medellín Textile Mills, 1935-1950. In J. French \& D. James (eds.), The Gendered Worlds of Latin American Women Workers: From Household and Factory to the Union Hall and Ballot Box (pp. 147-175). Durham: Duke University Press.

Fernández Álvarez, M. (2011). Além da racionalidade: o estudo das emoções como práticas políticas. Mana, 17(1). Recuperado de http://www.scielo.br/scielo.php?script=sci_arttext\&pid=S0104-93132011000100003\&lng=e $\mathrm{n} \& \mathrm{nrm}=$ iso

Fernández, M. L. (coord.) (2006). Las Flores, historias de la vida cotidiana (1856-1956) (Tomo II). La Plata: Instituto cultural de la Provincia de Buenos Aires y Municipalidad de Las Flores.

Fiorucci, F. (2013). Los amores de la maestra: sexualidad, moral y clase durante el peronismo. Secuencia, 85, 47-66. Recuperado de http://secuencia.mora.edu.mx/index.php/Secuencia/article/view/1180/1078

Frevert, U. (2011). Emotions in History - Lost and Found. Budapest and New York: Central European University Press.

Gil Lozano, F., Pita, V., Ini, G. (dir.) (2000). Historia de las mujeres en la Argentina. Siglo XX (Vol. I y II). Buenos Aires: Taurus.

Ginzburg, C. (1999) [1976]. El queso y los gusanos. El cosmos, según un molinero del siglo XVI. Barcelona: Muchnik Editores, S.A.

Ginzburg, C. (2010). El hilo y las huellas. Lo verdadero, lo falso, lo ficticio. Buenos Aires: Fondo de Cultura Económica.

Goodwin, J., Jasper, J. M. \& Polletta, F. (2001). Passionate politics. Emotions and social movements. Chicago: The University of Chicago Press.

Illouz, E. (2007). Intimidades congeladas. Las emociones en el capitalismo. Buenos Aires: Katz.

Illouz, E. (2009). El consumo de la utopia romántica. El amor y las contradicciones culturales del capitalismo. Madrid: Katz.

Johnson, L. (2007). A lack of legitimate Obedience and Respect: Slaves and their Masters in the Courts of Late Colonial Buenos Aires. Hispanic American Historical Review, 87(4), 631-657. https://doi.org/10.1215/00182 $168-2007-038$

Langhamer, C. (2013). Everyday love and emotions in the 20th century. In M. Hailwood \& B. Waddell (eds), The Future of History from Below: An Online Symposium. Recuperado de https://manyheadedmonster.wordpress.co $\mathrm{m} / 2013 / 08 / 28 /$ claire-langhamer-everyday-love-and-emotions-in-the-20th-century/

Lara, A. y Domínguez Giazú, E. (2013). El giro afectivo. Athenea Digital, 13(3), 101-120. Recuperado de https://ath eneadigital.net/article/view/v13-n3-lara-enciso/1060-pdf-es

Levy, G. (1993). Sobre Microhistoria. En P. Burke (ed.), Formas de hacer historia (pp. 119-143). Madrid: Alianza Editorial.

Lobato, M. Z. (1990). Obreras en la fábrica. El caso de las obreras del frigorífico Armour, 1915-1969. Anuario del IEHS, $V, 171-205$.

Lobato, M.Z. (2001). La vida en las fábricas. Trabajo, protesta y política en una comunidad obrera, Berisso (1904-1970). Buenos Aires: Prometeo.

Lobato, M. Z. (2007). Historia de las trabajadoras en la Argentina (1869-1960). Buenos Aires: Edhasa.

Lobato, M. Z. (2011a). Te amo, te odio, te quiero: una aproximación a la cultura afectiva de las clases populares en el Río de la Plata, 1880-1930. En G.B. Chicote y B. Göbel (eds), Ideas viajeras y sus objetos: El intercambio entre Alemania y América Austral (Vol. 46, pp. 339-349). Bibliotheca Ibero-Americana.

Lobato, M.Z. (ed.) (2011b). Manifestaciones, fiestas y rituales en el siglo XX. Buenos Aires: Biblos.

Lobato, M. Z. (2014). Afectos y sexualidad en el mundo del trabajo entre fines del siglo XIX y la década de 1930. En D. Barrancos, D. Guy y A. Valobra (eds.), Moralidades y comportamientos sexuales: Argentina 1880-2011 (pp. 155-174). Buenos Aires: Biblos.

Lobato, M.Z. (2017). Entre la historia social y la historia cultural: afectos y emociones entre las clases populares. Ponencia presentada en XIII Jornadas Nacionales de Historia de las Mujeres y VIII Congreso Iberoamericano de Estudios de Género, Buenos Aires, Argentina. 
Macón, C. y Solana, M. (eds.) (2015). Pretérito indefinido: afectos y emociones en las aproximaciones al pasado. Buenos Aires: Título.

Mayo, C. (2004). Porque la quiero tanto. Historia el amor en la sociedad rioplatense (1750-1860). Buenos Aires: Biblos.

Míguez, E. J. (1999). Familias de clase media: la formación de un modelo. En F. Devoto y M. Madero (dirs.), La Argentina plural: 1870-1930 (pp. 18-42). Buenos Aires: Taurus.

Mitidieri, G. (2018). Entre modistas de París y costureras del país. Espacios de labor, consumo y vida cotidiana de trabajadoras de la aguja, Buenos Aires, 1852-1862. Trashumante. Revista Americana de Historia Social, 12, 8-29. Recuperado de http://aprendeenlinea.udea.edu.co/revistas/index.php/trashumante/article/view/334120/207 90078

Moreno, J. L. (2004). Historia de la familia en el Río de la Plata. Buenos Aires: Sudamericana.

Palermo, S. (2007). ¿Trabajo masculino, protesta femenina? La participación de la mujer en la gran huelga ferroviaria de 1917. En M. C. Bravo, F. Gil Lozano y V. Pita (comps.), Historias de luchas, resistencias y representaciones. Mujeres en la Argentina, siglos XIX y XX (pp. 91-122). Tucumán: Editorial de la Universidad Nacional de Tucumán.

Palermo, S. (2013). En nombre del hogar proletario: Engendering the 1917 Great Railroad Strike in Argentina. Hispanic American Historical Review, 93(4), 585-620. https://doi.org/10.1215/00182168-2351647

Palermo, S. (2016). El derecho a mantener el hogar: las demandas obreras en la gran huelga ferroviaria desde una perspectiva de género. Argentina, 1917. En A. Andújar, L. Caruso, F. Gutiérrez, S. Palermo, V. Pita y C. Schettini. Vivir con lo justo. Estudios de historia social del trabajo en perspectiva de género. Argentina, siglos XIX y XX (pp. 81-101). Rosario: Prohistoria.

Pérez, I. (2014). Género y derechos laborales: servicio doméstico y trabajo doméstico no remunerado en la justicia laboral en la Argentina (1956-1974). Revista Páginas, 6(12), 67-82. Recuperado de http://revistapaginas.unr.e du.ar/index.php/RevPaginas/article/view/19/19

Pérez, I. (2017). Género y desigualdades en el mercado de trabajo: la desmarcación de los choferes particulares del servicio doméstico en la Argentina. Trabajo y Sociedad, 29, 25-39. Recuperado de http://www.unse.edu.ar/trab ajoysociedad/29\%20PEREZ\%20INES\%20Choferes\%20particulares.pdf

Pita, V. S. (2018). Auxilios, costuras y limosnas. Una aproximación a las estrategias de vida de mujeres en la ciudad de Buenos Aires. 1852-1870. Estudios del ISHiR, 20, 135-151. Recuperado de http://web2.rosario-conicet.gov.ar /ojs/index.php/revistaISHIR/article/view/828/912

Plamper, J. (2015). The History of Emotions. An Introduction. Oxford: Oxford University Press.

Putnam, L. (2013). Género, poder y migración en el Caribe costarricense 1870-1960. Costa Rica: INAMU.

Quinteros, G. O., y Cowen, P. M. (comp.) (2018). Familias de ayer y de hoy. Las sociedades ibéricas y el Río de La Plata. La Plata: FaHCE-UNLP. Recuperado de https://libros.fahce.unlp.edu.ar/index.php/libros/catalog/book/115

Rodríguez Molas, R. (1984). Divorcio y familia tradicional. Buenos Aires: CEAL.

Roper, M. (2005). Slipping out of View: Subjectivity and Emotion in Gender History. History Workshop Journal, 59, 57-72. https://doi.org/10.1093/hwj/dbi006

Rosenwein, B. H. (2002). Worrying about Emotions in History. The American Historical Review, 107(3), 821-845. h ttps://doi.org/10.1086/ahr/107.3.821

Sarlo, B. (1985). El imperio de los sentimientos: Narraciones de circulación periódica en la Argentina, 1917-1927. Buenos Aires: Catálogos.

Schettini, C. (2016). El negocio del prostíbulo: poder municipal y trabajo sexual. Buenos Aires, 1870-1887. En A. Andújar, L. Caruso, F. Gutiérrez, S.A. Palermo, V. S. Pita y C. Schettini, Vivir con lo justo. Estudios de historia social del trabajo en perspectiva de género (pp. 37-61) Rosario: Prohistoria.

Secreto, M. V. (2014). Pequenas histórias de sujeitos singulares. Río de Janeiro: Mauad X.

Simonetto, P. (2017). Fronteras del deseo. Homosexualidad, sociabilidad y afecto en la ciudad de Buenos Aires (1950-1983). Cadernos Pagu, 49. Recuperado de http://www.scielo.br/pdf/cpa/n49/1809-4449-cpa-1809444 9201700470014.pdf 
Smith-Rosenberg, C. (1975). The Female World of Love and Ritual: Relations between Women in NineteenthCentury America. Signs, 1(1), 1-29. Recuperado de https://www.jstor.org/stable/3172964

Suriano, J. (1983). La huelga de inquilinos de 1907. Buenos Aires: CEAL.

Suriano, J. (2001). Anarquistas, cultura y politica libertaria en Buenos Aires, 1880-1910. Buenos Aires: Manantial.

Tarullo, R. y Iacullo, A. (2013). Ferroviarios. Nuestra historia. Junín: UNNOBA.

Thompson, E. P. (1976). Folklore, Antropología e Historia social. Conferencia en el Indian History Congress. Recuperado de http://www.elsarbresdefahrenheit.net/documentos/obras/2184/ficheros/Thompson_Edward _1976_Folklore_antropolog_a_e_historia_social.pdf

Vidal, A. (1934). Historia de la ciudad de Las Flores. Buenos Aires: García Santos.

Zaragoza Bernal, J. M. (2013). Historia de las emociones: una corriente historiográfica en expansión. Asclepio, 65(1), 1-10. Recuperado de http://asclepio.revistas.csic.es/index.php/asclepio/article/view/547/572

Zemon Davis, N. (1982). El regreso de Martin Guerre. Barcelona: Antoni Bosch.

Zemon Davis, N. (1987). Fiction in the Archives. Pardon Tales and Their Tellers in Sixteenth-Century France. Standford, California: Standford University Press.

\section{Notas}

1 Si bien existe un debate en torno a las categorías y sus usos, en el presente trabajo empleo los términos afectos, emociones y sentimientos sin realizar distinciones teóricas.

2 D’Uva, Florencia, “Una aproximación a la cultura afectiva popular a partir de una denuncia policial. Las Flores, Buenos Aires, 1909", ponencia presentada en la mesa "Una palabra tuya... emociones y sentimientos en la primera mitad del siglo XX: variaciones latinoamericanas" de las XIII Jornadas Nacionales de Historia de las Mujeres y VIII Congreso Iberoamericano de Estudios de Género, 24 al 27 de julio de 2017, Buenos Aires.

3 La denuncia fue descubierta en el Archivo de una Jefatura de Policía del Norte de la Provincia de Santa Fe por el Dr. José R. Bergallo, juez de instrucción de Rafaela entre 1933 y 1937. Decidió publicar la trascripción íntegra de la misma en su libro Cuentos del Juzgado. Retrato del norte santafesino (Buenos Aires: Ediciones Anaconda, 1943) en el que reunió escritos producidos a partir de sus observaciones en los distintos departamentos del noroeste de Santa Fe, que recorría en sus actuaciones como juez. Actualmente, el Archivo Histórico Regional de Las Flores conserva una copia de la denuncia original.

4 Probablemente Angélica fuera parte del gran número de santiagueños que habitaban en Las Flores hacia fines del siglo XIX y principios del XX. Según consigna el censo nacional de 1869, muchos de ellos llegaban en caravana, cargados con productos como ponchos, mantas y cobijas para vender en la campaña bonaerense y algunos optaban por quedarse, conchabándose como peones en las estancias (Vidal, 1934, p. 131).

5 Se respeta la ortografía original de la denuncia.

6 Subrayado en el original.

7 http://www.lasflores.gob.ar/oficial/historia/

8 Un buen ejemplo, La Fraternidad, 01-09-1908, p. 7.

9 Según recuerda Ramón, quien ingresó al ferrocarril como peón practicante en 1948 con 17 años de edad, y llegó a ser auxiliar del jefe en Las Flores, las madres decían a las hijas: "Ese que va ahí es un buen candidato, ese es ferroviario" (Fernández, 2006, p. 51). Algo similar señaló Miguel Corujo, quien siguiendo el camino de su padre, en 1961 entró a trabajar en los talleres ferroviarios que el Ferrocarril Buenos Aires al Pacífico tenía en Junín. Según afirmaba, ser ferroviario era el mejor trabajo que había en Junín “porque se ganaba bien y conseguías un puesto estable”, y agregaba: “por eso, todos los padres querían que sus hijos fueran ferroviarios. Es más, los padres que tenían hijas luchaban para que se casaran con ferroviarios" (Tarullo y Iacullo, 2013, p. 28).

10 Entre distintos sectores de trabajadores, entre fines del siglo XIX y primeras décadas del siguiente, era común la condenación de estas prácticas. En los periódicos sindicales solían publicarse noticias en las que se advertía sobre los peligros del alcohol y el juego, y se contraponían estas prácticas a las de los trabajadores “conscientes”. De la cantidad de noticias en este sentido se puede inferir la existencia de una sociabilidad masculina que se desarrollaba fuera del hogar, en las tabernas, fondas y lupanares y que seguramente era condenada en público o ante determinada audiencia, pero largamente practicada en privado. 
11 Prueba de la situación de debilidad en que se encontraban las mujeres la constituye el hecho de que aproximadamente el $80 \%$ de las causas judiciales por disputas familiares (malos tratos, bigamia, adulterio, etc.) correspondientes al siglo XIX, en la región pampeana fueron iniciadas por mujeres (Moreno, 2004, p. 129).

12 Una síntesis del desarrollo de este campo de estudios se encuentra en Plamper, 2015 y Bjerg, 2019.

13 Como dijo Carlo Ginzburg (2010, p. 14), "si se indaga en el interior de los textos, a contrapelo de las intenciones de quien los produjo, pueden sacarse a la luz voces no controladas”.

14 Como señalan algunos autores, esto guarda relación con la consideración y construcción dualista que ha hecho el mundo occidental sobre las emociones como lo opuesto a la razón, que tiene su correlato en la división mente-cuerpo. Así, no solo el mundo de los sentimientos es separado, sino que también es subordinado y descalificado dado que se les adjudica un estatus inferior al de la racionalidad (Abramowski y Canevaro, 2017).

15 Es notable destacar que la gran mayoría de estas investigaciones centraron su atención en los grandes centros urbanos durante la primera mitad del siglo XX (Andújar, 2018).

16 Cabe señalar que en los últimos años son cada vez más las mesas que en congresos y jornadas invitan a pensar los afectos y emociones en clave histórica. Así, por ejemplo, en las XIII 2017 tuvo lugar la mesa de trabajo "Una palabra tuya... emociones y sentimientos en la primera mitad del siglo XX: variaciones latinoamericanas”, coordinada por Florencia Gutiérrez y Mirta Lobato. En noviembre de 2018 se realizó en Buenos Aires el IV Simposio Pensar los Afectos. Humanidades y Ciencias Sociales ante un Desafío Común con diversas mesas temáticas y ejes disciplinares que debatieron sobre el rol de los afectos/emociones en las humanidades y ciencias sociales. 